\title{
Legados coloniais e a produção de ambivalências: dos encontros, desencontros e conciliações em dois museus nacionais da Tanzânia, África.
}

Aline C. Rabelo

(UFRJ; EHESS)

\section{INTRODUÇÃO}

O National Museum and House of Culture (ou Makumbusho ya Taifa na Nyumba ya Utamaduni, na língua kiswahili) e o Village Museum (ou Kijiji cha Makumbusho) são os museus nacionais mais antigos da República Unida da Tanzânia. ${ }^{1}$ Criados a partir de projetos do empreendimento colonial britânico no Território de Tanganyika, estão ambos situados na cidade de Dar es Salaam, maior cidade tanzaniana e principal centro econômico do país. O primeiro priorizou substancialmente a coleta de objetos etnográficos durante o período colonial, embora sua atuação estivesse voltada desde o início para várias áreas do conhecimento. $\mathrm{O}$ segundo, um museu a céu aberto pensado para ser como que uma extensão da galeria etnográfica do primeiro (embora localizados em diferentes regiões da cidade), conformou-se na exibição de casas tradicionais de grupos étnicos tanzanianos.

As coleções etnográficas desses dois museus resultaram de processos históricos, tanto anteriores quanto posteriores à independência, em 1961, do Território de Tanganyika, sendo constituídas apenas de objetos provenientes de povos inscritos no território do país. A galeria etnográfica e seu formato ampliado (o "museu vila") foram concebidos para falar especialmente sobre esses povos. Não se tratam, contudo, de quaisquer grupos étnicos que ali se estabeleceram. Atribuiu-se um recorte político - cujo interesse se modificou de acordo com o período, conforme veremos - onde somente aqueles "originalmente africanos" deveriam ser representados e estariam representando o território colonizado, e, posteriormente, a nação.

Uma leitura atenta dos relatórios anuais ${ }^{2}$ do museu colonial King George $\checkmark$ Memorial Museum (como foi fundado o atual National Museum and House of Culture), nos permite identificar que a coleta dos objetos etnográficos naquele momento servia, de modo geral, a quatro objetivos principais do empreendimento 
colonial. Um dos mais explicitamente mencionados era a preocupação em "salvar" a cultura material dos povos africanos, que estaria em vias de desaparecer devido ao contato cada vez mais intenso com o ocidente. Aparentemente, era inevitável e não havia outro caminho esperado para o "primitivo" senão a apropriação da cultura ocidental e o abandono de sua própria, rumo à evolução. E igualmente graças ao europeu, a memória de sua diversidade cultural, por meio de suas últimas evidências materiais, poderia ser salva, documentada e preservada para a posteridade. O presente era coletado para virar passado - ou salvava-se do presente o que já era (deveria ser) passado. ${ }^{3}$

O mapeamento do território e os estudos realizados pelas sociedades científicas (tais como a Tanganyika Society, editora do jornal Tanganyika Notes and Records) também impeliram consideravelmente para o colecionismo (ou colecionamento) etnográfico, uma vez que os objetos coletados auxiliavam substancialmente na produção de conhecimento ocidental sobre aqueles povos colonizados, visando uma melhor gestão e controle sobre eles. Ainda, o projeto civilizatório-educacional, através das exposições da galeria, pretendia não apenas educar o olhar do africano, mas ensinar-lhe sobre o que ele deveria saber sobre si mesmo.

Talvez valha a pena considerar aqui que, apesar de todo esse processo de dominação evidenciado, é necessário olhar para a experiência colonial como um momento onde relações entre o colonizador e o colonizado são construídas. Isso significa dizer que, enquanto relação, não é apenas uma das partes que influencia a outra. (de L'Estoile 2008) Embora seja indiscutível que as relações sejam assimétricas e configuradas, na maioria das vezes, por um acentuado desequilíbrio de poder, e apesar das denominações dualistas (colonizador vs colonizado, dominador $v s$ dominado etc), o fluxo interacional não ocorre sempre de forma impositiva e somente em um sentido (Tsing 1993). Precisamos atentar para o que pode ser produzido dessa relação mútua.

Sem entrar na questão da aqui incontestável capacidade de agência, resposta e proposição por parte do colonizado, gostaria de chamar a atenção para os processos desencadeados por essas relações coloniais. Se, por um lado, gestores, pesquisadores e administradores europeus estavam construindo definições sobre os africanos, estavam, ao mesmo tempo, encontrando formas de definirem-se a si mesmos - e isso incide nas categorizações e hierarquizações "em casa", ou seja, nos processos de domesticação comparativa também na metrópole (Comaroff \& Comaroff 1992). A colonização na África não agiu apenas na ordenação do mundo do nativo, mas na própria ordenação do universo britânico a partir das relações coloniais que foram sendo construídas.

É nesta direção que Benoît de L'Estoile (2008) traz o conceito de legados coloniais, não como algo prédeterminado (comumente negativo e radical), e sim como algo assentado na mutualidade das relações coloniais estabelecidas a longo prazo. E é com base nessa noção que proponho olharmos para os desdobramentos do colecionamento etnográfico ocidental na Tanzânia - ou seja, para as reapropriações e ressignificações de espaços e práticas museológicos, a contar da independência do país -, a fim de direcionarmos nossa atenção aos processos desencadeados a partir de contingências relacionais, sem inferirmos que estes estariam condicionados ao período colonial. 
Tal exercício não nos impede, contudo, de enxergarmos continuidades e convergências. Representações que começavam a ser construídas naquele momento nos museus coloniais conduziam a determinados modos de institucionalização de formas identitárias atribuídas aos grupos étnicos mapeados. Classificações e ratificação de distinções entre o que deveria ser considerado etnográfico naquele contexto (eg. olaria africana) e o que deveria ser histórico (achados arqueológicos de cerâmica chinesa, por exemplo) contribuíam como mecanismos de delimitação das alteridades.

O outro sobre quem se falava nos museus não era "qualquer outro", não europeu; nem "qualquer outro" não europeu que habitasse no Território de Tanganyika (mesmo que há décadas ou centenas de anos, como os indianos e árabes, respectivamente). 0 etnográfico dizia respeito àquele outro específico: o que sempre esteve ali.

\section{- SEÇÃO UM -}

\section{Quando os Outros viram Nós}

Com a independência de Tanganyika e sua subsequente união ao arquipélago de Zanzibar, em 1964, a nacionalização do museu ${ }^{4}$ resituou as coleções etnográficas. Não me refiro a mudanças na composição dos acervos e no modo como os objetos eram concebidos em exposição, pois não houve alterações imediatas substanciais. $\mathrm{O}$ discurso - e a construção de um "moderno" edifício de ampliação do museu - é que atribuía novos sentidos à exibição da cultura material das "populações originárias", agora não apenas como instrumento de reapropriação de suas narrativas e produção simbólica da autonomia, diante da experiência colonial, mas porque o movimento de afirmação e valorização da diversidade étnica local - africana - ia ao encontro do projeto de construção da nova comunidade política imaginada. ${ }^{5}$

Acredito ser potencialmente ilustrativo reproduzir alguns trechos do catálogo do National Museum of Tanzania (nome do museu quando nacionalizado), impresso em 1974, dez anos após a formação da República Unida da Tanzânia:

It may seem strange that a new nation with a big task of nation building ahead, should consider a museum among its priorities. But this is in line with the thinking of the country's first President, Mwalimu Julius Nyerere, that Culture is the soul of a nation. [...] (Kirknæs \& Wembah-Rashid 1990 [1974]: 5)

Abro um parêntese aqui para uma breve reflexão acerca dessa sugestão de uso indissociável das ideias de cultura e nação. Primeiramente: o que se compreende por nação? Se há pouco fiz alusão a uma definição de Benedict Anderson (1983), quase exatamente um século antes o filósofo francês Ernest Renan proferia uma palestra cujo título apresentava justamente a questão: "Qu'est-ce qu'une nation?" (O que é uma nação?).

Em linhas gerais, Renan (1990 [1882]) respondeu à sua pergunta ressaltando que nação seria um contrato ou uma associação voluntária e consciente de seus membros diante de uma herança histórica compartilhada e da afirmação coletiva de valores em comum. Comentando a definição de Renan, Kenan Malik (1996) identifica em sua 
concepção uma dicotomia, uma vez que Renan se utiliza tanto da acepção francesa iluminista de nação - caracterizada por ideias universalistas e contrárias a interesses particulares -, quanto de tradições do Romantismo alemão - que toma crenças particularistas e se assenta na noção de uma comunidade pré-determinada ligada pelo sangue e pela hereditariedade. Enquanto o primeiro discurso se afasta de classificações e conceitos racialistas, trazendo as diferenças humanas em termos de cultura, o segundo fala a partir de categorizações raciais (Malik 1996:131). O que Malik então contesta é que Ernest Renan, ao mesmo tempo em que traz algumas ideias universalistas, desliza seu discurso substancialmente para as concepções românticas de nação, enfatizando a compreensão de que as condições essenciais para a existência de um povo estão localizadas nos ancestrais em comum, no passado compartilhado e em expectativas comuns para o futuro.

Esse apontamento da transformação do conceito de nação, que se dava no século XIX, teria contribuído para uma transformação da noção moderna de cultura, a qual, conforme destaca Malik, passou a se relacionar muito estreitamente com a ideia de raça. Lá nas ideias de Renan e de seus contemporâneos, já era possível identificar noções que permeariam embasamentos evolucionistas e o próprio relativismo cultural, imbuído de valores positivistas sobre a diferença.

A transformação da ideia de nação e a ampla adoção do conceito particularista foram estimulados, segundo Malik, por vários fatores a partir da segunda metade do século XIX, dentre eles, o desenvolvimento do estado moderno e de suas instituições, a industrialização, o crescimento da classe trabalhadora e a intensificação dos conflitos de classe, a intervenção do estado na economia nacional - e poderíamos incluir aqui o imperialismo europeu e colonização da África e da Ásia, além das duas grandes guerras mundiais da primeira metade do século XX. Nesse sentido, Malik complementa pontuando:

It was not until the second half of the century $[\mathrm{XIX}]$ that the nation began to be seen predominantly in 'closed' terms and that the distinction between citizen and foreigner became crystallized both in popular and in official language. It was now that the idea of a homogenous national culture and of a nation as the embodiment of an organic history and heritage began to take hold. The nation became less the product of a voluntary political association than the incarnation of a particular ethnic, linguistic or racial identity. (1996:137)

Essa breve análise histórica que recupera algumas das transformações nos usos e concepções acerca da nação é elucidativa para a compreensão de alguns dos princípios que foram norteando a emergência de nações e a construção de valores nacionais. Nos contextos africanos, em função das especificidades da experiência colonial, outros aspectos apareceram também em jogo no pós-independência. Como se contrapor ao capitalismo ocidental trazendo modernidade para a nova nação? Como pensar em uma homogeneização cultural em meio à tamanha diversidade étnica? Que alma teria a nação tanzaniana? Para quem essa nação deveria ser construída?

A solução trazida pelo Mwalimu [professor] Julius Nyerere - primeiro presidente tanzaniano, chamado de "pai da nação" - era um novo modelo de desenvolvimento, o socialismo africano Ujamaa. Instituído por meio de um documento intitulado The Arusha Declaration, em 1967, o Ujamaa tinha o intuito de produzir um rápido progresso econômico e social - e, para isso, Nyerere promovia ideias humanistas de igualdade para todos e contava com um 
eficiente discurso moral, baseado na noção de solidariedade e da força de trabalho coletivo. $\mathrm{O}$ direito ao usufruto da terra e dos recursos naturais por toda a comunidade, com a proibição de compra ou venda de terrenos, tornouse um fundamento de sua política territorial. ${ }^{7}$ Mas mais do que um modelo econômico de desenvolvimento, o Ujamaa foi a principal política de construção da unidade nacional tanzaniana. ${ }^{8}$

Retornando ao catálogo do National Museum of Tanzania, observamos que o museu nacionalizado passa a ser um instrumento de implementação do projeto do novo Estado socialista:

[...] The old Museum was a colonial institution for showing how 'primitive' the 'native' was. The National Museum is a national, cultural, educational and scientific centre where Tanzanians learn about their past for understanding the present and forming aspirations for the future. This is crucially important in a socialist state where rapid change is required and everything must be planned. It is a museum that will strengthen the spirit of nationalism and African unity and make the Tanzanian feel proud of himself as a true son of Africa. (Kirknæs \& Wembah-Rashid 1990 [1974]: 5)

É necessário, aqui, pontuar um aspecto importante a respeito da configuração populacional no pósindependência. Na emergência do Estado nacional tanzaniano, europeus, árabes e "asians" (indianos e paquistaneses) já ocupavam marcadamente um lugar na sociedade - e de mais privilégios que a maioria africana. Entretanto, não pareceu interessante incorporá-los ao arcabouço da nação apresentado pelos museus no processo de nation building - não enquanto povos cujas culturas devessem ser exaltadas e transformadas em motivo de orgulho. Nesse período, houve uma forte insurgência de políticas que propunham ações afirmativas (sobretudo econômicas) apenas para os africanos. As ideias de "africanização" e "indigenização" formaram frentes de grande disputa política por direitos exclusivos, procurando pautar quem estava incluído no "nós" e quais eram os outros "de fora" (Heilman 1998; Aminzade 2001). Atualmente, no National Museum and House of Culture, encontramos os grupos de origem não africana localizados apenas na galeria histórica, onde estão atrelados às narrativas de ocupação do território, escravidão, exploração e colonização.

Para a criação de identidades nacionais, mostrava-se necessário recorrer a valores "genuinamente africanos", àquilo que seus povos originários foram capazes de lhe imputar e fazer sobreviver mesmo com o advento da opressão colonial. Foi nessa direção que se recorreu ao período pré-colonial, às tradições culturais, e, portanto, às populações autóctones, as quais ofereciam não apenas significados para a construção de uma identidade nacional, mas possibilidades de reconhecimento de uma "cultura continental" africana (Mazrui 2010) ${ }^{9}$. O nacionalismo, então muito influenciado pelas teorias pan-africanistas, passa assim a evocar e ratificar as "raízes africanas", o sentimento de orgulho de ser "a true son of Africa"; utiliza-se de um "continentalismo", ou da existência de uma "africanidade", para auxiliá-lo nesse processo de criação de uma unidade cultural nacional.

A "africanidade", encontrada nas formas mais ordinárias do "modo de vida tradicional", assumindo os contornos locais (nacionais) a partir de especificidades étnicas atreladas às histórias contadas pelos objetos etnográficos, passa a ser acionada como identidade coletiva, excluindo simbolicamente do coletivo nacional todos aqueles que remetem a um passado de dominação. As coleções carregam consigo a memória da relação de exploração colonial; os objetos tradicionais que antes eram utilizados para falar do outro, inferiorizado e exótico, agora são reapropriados para falar de si. 


\section{Identidades: manipulação das semelhanças e dessemelhanças}

Fazendo uso da referência de Simon Harrison (2003) sobre a tese central do trabalho de Chatterjee (1986), este pontua que movimentos nacionalistas em várias partes colonizadas do mundo reivindicaram a libertação da dominação europeia se utilizando justamente de modos europeus de pensamento político (Chatterjee 1986; 1993 apud Harrison 2003:355). A fim de negar as semelhanças com modelos ocidentais, pensadores e líderes africanos procuraram atribuir diferenças aos seus nacionalismos contrapondo seus valores espirituais às motivações essencialmente materialistas de seus colonizadores. Este é apenas um dos exemplos acionados por Harrison para defender seu argumento de que o apagamento de semelhanças serve como mecanismo para construção da diferença entre grupos étnicos ou nações.

De acordo com Harrison, no terreno do nacionalismo ou da etnicidade, as diferenças culturais refletem, na realidade, as relações sociais. O autor parte da compreensão, trazida em 1969 por Barth, de que os grupos étnicos (e mesmo as nações) são definidos a partir da diferença cultural, ou seja, das "dissimilarities (of culture, history, mentality, physical appearance and so forth) imagined or perceived to exist between itself and others" (Harrison 2003:343). As identidades, construídas a partir do contraste, dependem de processos de exc/usão para existirem e se afirmarem diante do "outro marginalizado". Entretanto, o que Harrison procura salientar é que a construção dessas diferenças, muitas vezes, se assenta na negação, na obliteração ou no apagamento das semelhanças, havendo, portanto, um gap entre a "diferença imaginada" e a "similaridade objetiva". Não sendo neutras, as diferenças ressaltadas comunicam avaliações e julgamentos de valor - é o que Harrison descreve através dos "modelos de silenciamento da semelhança", os quais construiriam as dessemelhanças a partir de valorações quanto à inferioridade, superioridade ou igualdade do "outro" em relação a "si".

Essa reflexão de Harrison nos permite analisar dois movimentos coincidentes e paradoxais nos museus nacionais tanzanianos. O primeiro atua reconhecendo semelhanças entre os grupos étnicos tanzanianos, a fim de criar uma diferença contrastante em relação aos "outros" - estrangeiros externos e internos. O segundo reifica dessemelhanças desses povos tradicionais também como forma de se produzir uma identidade nacional. Aparentemente ambíguos, os dois propósitos servem aos interesses de consolidação do Estado nacional tanzaniano: pela homogeneização, estabelece-se uma unidade sustentada pelo compartilhamento do "modo de vida tradicional africano"; pela afirmação da heterogeneidade, a diversidade dos mais de 130 grupos étnicos africanos inscritos no território nacional se preserva (sem entrar aqui em um outro debate que seria o das disputas e questões interétnicas entre os grupos africanos) e conforma a ideia de uma nação que se enxerga e se orgulha de ser "culturalmente rica" ${ }^{\prime \prime}$. 


\section{Museu (nacional) para que $(\mathrm{m})$ ?}

Mas o "modo de vida tradicional" já era o eixo que concebia as exposições de ambos os museus desde o período colonial - obviamente, como vimos, dentro de objetivos bastante diferentes. Inicialmente, as propostas dos museus se diferenciavam em função dos públicos distintos aos quais se direcionavam.

Quando a então curadora do Zanzibar Museum, Nicol Smith, foi convidada no início da década de 1940 a organizar o display etnográfico do recém fundado King George V Memorial Museum, havia a ideia principal de que o arranjo dos objetos deveria levar em conta o fato de que grande parte da comunidade local nunca tinha estado em um museu antes na vida. Portanto, a experiência da visita à exposição deveria ser, sobretudo, visual, uma vez que a instrução do público se fazia possível a partir deste tipo de contato com os objetos:

“The fundamental principle in the display of the specimens in either museum [Zanzibar Museum e King George V Memorial Museum] is the belief that the material exists as a means of visual instruction. Each exhibit therefore attempts in the first instance to attract the eye and in the second to enable the brain easily to assimilate its content." (Meyer-Heiselberg 1972:16)

O africano, para ser instruído, precisava ser educado através do olhar. Assim, as exposições tinham como foco o objeto - até hoje, os objetos continuam tendo mais destaque do que os poucos e pequenos textos. As peças, organizadas por seções temáticas relacionadas a práticas da vida "tradicional" (caça, pesca, agricultura, utensílios domésticos, medicina tradicional, instrumentos musicais, olaria, fumo...), de um modo bastante similar aos agrupamentos atuais, também contribuíam com a proposta de privilegiar os objetos em detrimento dos textos.

No Village Museum, apesar da centralidade estar na experiência do contato com o objeto, o estímulo não foi concebido para ser apenas visual. Não me refiro somente aos textos, encontrados na entrada de cada uma das casas, pois mesmo que eles existam e sejam parte significante da contextualização dos grupos étnicos e suas respectivas arquiteturas e práticas tradicionais, esse recurso está notavelmente em segundo plano. Nesse museu a céu aberto, o conhecimento sensorial é ainda mais estimulado, uma vez que o público é convidado a interagir, em certa medida, com seus objetos principais - as casas. Mas há que se considerar a sutil [sic] diferença de que público é esse, ou seja, para quem o Village Museum foi primordialmente pensado. Sendo o visitante o turista estrangeiro ocidental, a experiência possibilitada pelo contato com o objeto não está aqui conectada à noção de uma suposta incapacidade de seu público em apreender qualquer conteúdo, mas à oportunidade dada ao turista de perceber o exótico de modo mais aproximado. Cada casa passa a ser uma pequena aventura para o turista estrangeiro e o objeto é, essencialmente, o que torna essa vivência possível.

Com a nacionalização dos museus, a introdução do discurso nacionalista passou a funcionar de modo concomitante à forma como os museus se comunicavam com o público turístico. Os estrangeiros (sobretudo brancos ocidentais) continuavam mostrando-se interessados pelos objetos etnográficos, seja buscando sua aquisição, seja sua contemplação (ou experimentação) nos espaços museológicos quando de passagem pela cidade de Dar es Salaam. 
Normalmente, os turistas procuram a Tanzânia muito em função de seus parques nacionais, onde é possível fazer os safaris e entrar em contato com "a vida selvagem". Ainda, outros grandes atrativos são o Monte Kilimanjaro e o arquipélago de Zanzibar, conhecido mundialmente pelas suas praias e pela predominância da cultura Swahili. Neste circuito turístico, Dar es Salaam muitas vezes serve de local de passagem para os turistas que seguem para o norte ou que se encaminham para Zanzibar.

Os museus de Dar es Salaam participam, assim, da não muito extensa lista de "highlights" comumente designada ao turismo na cidade, a partir da qual, para visitantes que dispõem de pouco tempo, o Village Museum costuma ser priorizado devido ao seu apelo turístico mais expressivo.

Identificando o potencial econômico dessas instituições em atrair visitantes estrangeiros, o Governo tanzaniano passou a localizá-los dentro da alçada do Ministério dos Recursos Naturais e Turismo. Essa vinculação explicita as diretrizes políticas e valores que vêm sendo ratificados continuamente nos últimos quinze anos. A transferência de atribuição dos "cultural heritage resources", que por duas vezes estiveram vinculados ao Ministério da Educação ao longo de dezessete anos, para a até então definitiva alçada do Turismo, revela uma mudança significativa na concepção da importância destinada ao "patrimônio cultural material tanzaniano".

Os gestores dos museus passaram, então, a investir mais na oferta de serviços aos turistas: lojinhas de souvenirs, restaurantes que servem "local food", artesanato local. No Village Museum, um artista autônomo ocupa, há décadas, a frente de uma das casas para vender suas esculturas. Petro Mayige faz miniaturas das casas tradicionais representadas no museu a céu aberto, além de esculturas em argila de mulheres, homens e crianças realizando atividades cotidianas "tradicionais". Segundo o artista, ele procura mostrar com seu trabalho o modo de vida nas vilas rurais tanzanianas em geral, a partir de cenas observadas repetidas vezes.

As esculturas de Mayige comunicam, porém, mais do que um cotidiano da vida rural tanzaniana, mas uma romantização desse modo de vida, onde todos se mostram felizes e em harmonia nos afazeres de suas atividades diárias. Depois de algum tempo de convivência com Mayige, percebi que sua arte está estreitamente conectada à sua própria concepção de vida ideal, muito influenciada pela herança ideológica do Ujamaa.

O trabalho de Petro Mayige depende, fundamentalmente, dos turistas estrangeiros. De acordo com ele, os tanzanianos não se interessam muito por arte. Isso não quer dizer que não parem para admirar seu trabalho ou que não o apreciem; eles acham as esculturas caras e simplesmente não veem utilidade em adquiri-las: "Se desejam enfeitar suas casas, os tanzanianos preferem comprar flores", observa Mayige. Além disso, o artista percebeu que trabalhar esculpindo na frente dos turistas era uma estratégia eficiente. Era como o atestado de que poderiam adquirir uma "autêntica obra de arte africana".

Há, ainda, outro tipo de produto "artístico-cultural" à disposição para o consumo dos turistas no Village Museum: as apresentações de danças tradicionais de grupos étnicos tanzanianos. Cotidianamente, grupos de dançarinos e percussionistas se apresentam sob a demanda dos visitantes. Um deles, por exemplo, é formado apenas por senhoras, a maioria da etnia Makonde. Um outro, composto por jovens, mistura danças tradicionais de vários povos com um trabalho de criação autoral de alguns dos dançarinos. 
São vários os subsídios específicos para falar sobre os atrativos turísticos no Village Museum, mas um ponto que eu gostaria de destacar brevemente é o fato de as coleções etnográficas africanas fazerem parte de um imaginário ocidental específico e serem objeto de interesse ocidental. Isso decorre, em grande medida, em função das imagens de exotização que foram sendo construídas e alimentadas pelas práticas colecionistas coloniais, pela emergência das galerias e dos museus etnográficos na Europa e pela própria disciplina antropológica (Stocking 1988; Thomas 1991; De L'Estoile 2010, 2011). Ainda, a vinculação do conceito de arte aos objetos etnográficos (e seus desdobramentos, como a proliferação do ávido mercado de arte africana) e outras classificações estéticas ocidentais incidiram - incidem - sobre esses museus africanos, notavelmente percebidas através do turismo.

\section{Além de museum, makumbusho ${ }^{11}$}

Um dia ouvi do curador do Village Museum: "Neste museu, você sente que está, de fato, na Tanzânia. Aqui dentro você visita todo o país sem precisar viajar. Esta é a nossa intenção". Essa afirmação, que talvez possa oferecer à primeira vista uma conotação mais circunscrita ao turismo, se expande e vislumbra propósitos mais amplos do museu através de outra fala, durante uma visita guiada ${ }^{12}$. Segundo o guia, seriam três as razões principais pelas quais o Village Museum se apresenta reunindo mais de trinta casas tradicionais em um único espaço: 1. Para mostrar e possibilitar uma comparação entre os diferentes tipos de arquitetura tradicional da Tanzânia para estrangeiros e tanzanianos; 2. Reduzir os gastos financeiros do turista ou do tanzaniano que pretende visitar todas as regiões do país para conhecer os diferentes modos de vida tradicionais; 3. Possibilitar um acolhimento do tanzaniano que vem do meio rural para a cidade e pode reconhecer ali, no museu, um pedaço de seu universo, de sua origem.

Mas esse acolhimento não se configura apenas pela possibilidade de o(a) tanzaniano(a) poder visitar o museu quando estiver "com saudade de casa", como me explicara o guia. Nem tampouco por meio de uma imaginada identificação que ali procura ser incutida através de ideias e emblemas nacionalistas reificados. O tanzaniano parece estar contemplado na proposta do Village Museum fundamentalmente devido a um programa desenvolvido anualmente, chamado "Siku ya Utamaduni wa Mtanzania" ou "Tanzanian Cultural Days Festival".

O programa foi idealizado em 1993 e implementado em 1994, sob o nome "Ethnic Days Programme", durante uma fase em que o Museu estava ainda em processo de ampliação de seu acervo - sobretudo no que diz respeito à construção das casas. Grupos de pessoas de algumas etnias eram convidados a apresentar alguns de seus "aspectos históricos e culturais de seu povo", através da construção de suas respectivas casas (utilizando matéria-prima de suas regiões originais), da preparação de comidas e bebidas, da exibição de objetos e danças tradicionais. Durante os dois ou três dias do evento, nas atividades estavam também inclusos seminários e debates sobre as principais questões sociais e econômicas apresentadas pelo grupo étnico participante ${ }^{13}$. (Kayombo 2005; Msemwa 2010). ${ }^{14}$

O Ethnic Days Programme constituiu-se a partir de diretrizes apontadas pelo então Board of the National Archives, subordinado ao Ministério da Educação e Cultura, que visavam criar oportunidades para que os diferentes 
grupos étnicos do país pudessem "apresentar suas culturas" no Village Museum. Houve, entretanto, certa cautela na implementação do programa. Alguns membros do Governo acreditavam que ele poderia fomentar o tribalismo e estimular o aparecimento de conflitos (Mpangala 1998 apud Msemwa 2010). Levando isto em consideração, uma equipe especializada, que incluía acadêmicos, antropólogos e líderes de alguns grupos étnicos, foi formada para pensar nas estratégias de execução do Ethnic Days e nos pressupostos de relevância que o programa traria.

Dois foram os pontos essenciais para o êxito da realização do programa: a identificação de que seria fundamental o estabelecimento de um diálogo com articuladores da comunidade local de Dar, os quais serviriam como ponte inicial entre seus respectivos povos e o Governo (e sua instituição museológica); e a sustentação da identidade nacional baseada na diversidade étnica como instrumento de reafirmação e permanente (re)produção da unidade nacional imaginada.

A apresentação das chamadas "práticas tradicionais" das várias etnias tanzanianas e os debates acerca das principais questões levantadas por eles contribuiria para a promoção da "harmonia nacional" através da oportunidade de conhecimento, compreensão e de uma sensibilização para as práticas e cosmologias das outras comunidades tanzanianas:

Through this programme people of different ethnicities learn from other groups what they value most and stand for; it opens up dialogue and understanding. Through this program the people and their government have come to learn and to appreciate the fact that each person is proud of his/her identity, history and culture, and that conflicts are often rooted in one's ignorance of the other. (Mpangala 1998; Msemwa 1998, 1999 apud Msemwa 2010).

Outro objetivo viria a ser relacionado ao esforço em fazer do Village Museum "um retrato íntimo da vida dos tanzanianos". Se esta imagem muito interessa ao turismo, parece interessar também, por outro lado, tanzanianos, conforme sugerira o guia e fora reconhecido como resultado proporcionado pelo programa: os tanzanianos se apropriam do espaço do Village Museum e tomam-no como seu; sentem-se "em casa". ${ }^{15}$

Depois de vinte anos de programa (agora chamado de Tanzanian Cultural Days Festival), é comum que membros dos próprios grupos étnicos procurem o Museu para declararem seu interesse em participar do projeto. Contudo, o trabalho de divulgação por parte do Museu continua sendo executado, pelo próprio curador, naquelas regiões onde se verifica que não houve ainda uma manifestação voluntária:

Promotion campaigns are awareness campaigns [that] I do in respective communities and it involves meeting with regional commissioners, regional and district cultural officers and elders of the communities. I present to them the importance of their culture and traditions, my job as ethnographer, and the need to identify, learn, maintain, promote and inherit their culture to present and future generations one being to do the cultural festival and preserve or exhibit the cultural artifacts at the Village Museum. [...] Where community accepts, I work with them to find sponsors, do promotion on media etc. ${ }^{16}$

É possível observarmos na fala do curador que o discurso não aparece mais apoiado substancialmente na prerrogativa de conhecimento mútuo entre os grupos étnicos para a erradicação de preconceitos, conforme se assinalava na fase antecedente, e sim na necessidade de ratificação da importância e preservação da singularidade 
das "culturas e tradições". Mais além, o método de apresentação do programa funciona enquanto ação que legitima a existência e o valor do grupo perante o Estado, procurando demonstrar uma preocupação com a inclusão mais democrática das comunidades ${ }^{17}$ tanzanianas. Cabe, porém, ressaltar que não dispus de métodos, quando em campo, para identificar se essa política estava alinhada a diretrizes recentes mais amplas de instâncias ministeriais ou se era produto de uma gestão mais autônoma definida pelo próprio museu.

O Festival, incluindo suas etapas de prospecção, os dias de evento em si e a visibilidade criada por ele, é fundamental, ainda, enquanto construção de um processo dialógico, onde os tanzanianos são parte indissociável das renovações do acervo do museu e da produção de informações sobre os grupos étnicos. À medida que o programa vai ampliando seu alcance, as pessoas passam a doar, voluntariamente, objetos entendidos como representativos de seus grupos (seja no meio urbano ou rural), além de fornecerem informações sobre eles, tais como nomes e formas de utilização em seus contextos de origem. ${ }^{18}$

Mas se o Village Museum consegue servir ao turismo internacional e, ao mesmo tempo, ser espaço de produção e consolidação de identidades através do encontro e da participação dos tanzanianos, no National Museum and House of Culture - antes de assim se chamar - a situação era outra:

In 2002, a study conducted on visitation and public perception of the museum (NMT, 2003) revealed that the National Museum Dar es Salaam (the museum's name since 1980) was under-utilised by the local population. People felt it was boring and that it was meant for foreign tourists. These findings and visitors' statistics indicated that a very small number of the more than 2.5 million people living in urban Dar es Salaam actually used the museum; the local communities could rarely identify with it. Indeed, these findings contradicted the museum's expectations. (Msemwa 2010:16).

Parte de um processo conduzido pelo curador Paul Msemwa, esse estudo foi justamente uma das primeiras ações que levou à constatação de algo que vinha sendo percebido no National Museum Dar es Salaam ${ }^{19}$ e que se contrastava com a experiência do Village Museum: a comunidade local estava distante porque não se interessava pelo museu e não se identificava com o que ele propunha ao seu público. Se antes Msemwa tinha sido um dos principais responsáveis pela implementação do Ethnic Days, agora era convidado novamente a pensar em um processo igualmente dialógico e participativo para o National Museum Dar es Salaam, que reconsiderasse a construção de uma relação entre a comunidade local e o museu. De acordo com os trabalhos que já havia realizado, Msemwa concluía que "once people are engaged and involved, listened to and their views respected, they are willing to take part, to share experiences and to contribute significantly with their knowledge and resources." (2010:18).

Identificou-se que o que mais atraía o público local eram as exposições sobre escravidão e colonialismo, além das apresentações de performances tradicionais, temáticas que, segundo Msemwa (idem), permanecem, em grande medida, atribuindo contornos às relações sociais e econômicas. O processo dialógico de compartilhamento de demandas e expectativas das partes envolvidas apontou que o museu precisava ser entendido como um espaço mais dinâmico, que pudesse despertar o interesse das comunidades locais e ser apropriado por elas através de 
processos que propiciassem novas formas de identificação. Isso demandaria que ele se transformasse em um espaço de convivência, lazer, aprendizado, troca de experiências e de ideias - algo que comumente se assemelharia às propostas das chamadas "casas de cultura".

Chegava-se à conclusão de que então fazia sentido unir sob um mesmo espaço físico duas concepções que não costumam ser vistas como coincidentes:

The facilities' stakeholders demanded that it must include an auditorium for performances, a space for storytelling, a children's library, a music recording studio, a dance rehearsal hall, a space for temporary exhibitions, a restaurant for traditional dishes, improved permanent exhibitions, expanded collections storage and an office space. Museum collections, the stakeholders argued, should inspire the production of performances, exhibits, films and programmes that address contemporary social and economic issues. (Msemwa 2010:19)

Aqui nos deparamos com um ponto fundamental da relação que precisava ser ressignificada. Ao Museu não cabia continuar servindo apenas aos interesses e à admiração do Governo, dos turistas e dos próprios profissionais da instituição; ele deveria ser disponibilizado de fato para o uso efetivo da população. A percepção dos "stakeholders" passava por uma chave que atribuía às coleções museológicas uma função catalisadora na produção de reflexões e proposições sobre temáticas contemporâneas. Ao Museu caberia fazer inspirar. A Casa de Cultura seria, assim, o espaço onde os desdobramentos e criações se fariam possíveis, onde as conexões pudessem ser coletivamente vivenciáveis e o sentimento de pertencimento fosse presente.

\section{CONSIDERAÇÕES FINAIS}

A metodologia dialógica é um desenvolvimento de um dos principais tópicos introduzidos pela Nova Museologia: a questão da participação, do envolvimento das comunidades locais e outras partes interessadas - conhecidas pela noção e categoria "stakeholders" - nos processos de reflexão acerca dos projetos museológicos. O que impulsiona tal metodologia é a possibilidade de melhor conhecer, respeitar e considerar as diferentes perspectivas dos atores envolvidos. Obviamente que essa escolha pelo compartilhamento de reflexões, pontos de vista, demandas e até mesmo decisões não se apresenta como uma tarefa simples; impõe muitos desafios e negociações. E é isso que justifica em parte que, mesmo não sendo uma proposta tão recente (o movimento da nova museologia despontou na década de 1980), as tentativas ainda sejam, de certo modo, novidades, "experiências", "casos", enfim, processos únicos, por variarem conforme as especificidades dos contextos. ${ }^{20}$

Desde que foram criados, os dois museus tanzanianos passaram por muitas transformações, menos no que se referem aos seus acervos etnográficos e mais em termos de funções e discursos. Quando fundado, por iniciativa da administração colonial, mas com metade dos recursos doados pelas próprias comunidades locais (a maioria de africanos) ${ }^{21}$, o King George V Memorial Museum se apresentava como voltado para a comunidade local, que, neste caso, era entendida como sendo os africanos - mesmo que se verificasse que, em muitas fases, eram os "asians" os visitantes mais frequentes, além dos europeus, em menor número. Depois, o NMT também se direcionava para a comunidade, que agora era a nação e entendida como formada pelos "true sons of Africa". 
Mais recentemente, os museus passaram a ser destinados para as comunidades, locais e nacionais, que aceitassem a proposta de construírem coletivamente novas significações.

Embora outros grupos tenham se beneficiado desses museus tanto ou mais que "a comunidade", ambas as instituições estiveram sempre voltadas, teoricamente, para as comunidades. Mas somente quando da introdução de metodologias dialógicas é que os tanzanianos puderam experimentar o efeito dessa preposição "para", paradoxalmente não mais unidirecional. Talvez então tenham se sentindo mais contempladas, mais parte de um processo que dizia falar delas e para elas. A questão da identificação é chave aqui, a partir do momento em que vínculos começam a ser criados, de variadas formas, com esses espaços - pois é importante ressaltar: a criação institucionalizada de identidades não conduz, necessariamente, a uma identificação.

Poderíamos dizer, assim, que nessas duas últimas décadas estes museus se transformaram naquilo que as novas práticas museológicas conceberiam como "museus comunitários"? Mas museus nacionais podem ser ao mesmo tempo comunitários? Conforme ressalta Rassool (2010) as definições sobre o que vem a ser um "community museum" giram muito em torno dos debates da própria noção do que seja uma comunidade. Na maioria das vezes, pensa-se museu comunitário a partir de enquadramentos étnicos, ou restritos a uma localidade ou origem comum, independentes do Estado, ou comprometidos (como que paternalmente) com a inclusão social de comunidades definidas geograficamente. No entanto, Rassool nos convida a refletir sobre o que parece ser mais promissor nesse modelo de community museum:

[...] community museums become more effective when they explore forms of co-ownership, through dialogic and transactive methods. This requires systems of governance which ensure that community museums exist not only for communities, but of communities. This also requires new museum methods that enable the disciplines of conservation and stewardship to engage with other knowledge forms held within the communities themselves. Scholars refer to these relations through notions of 'shared authority' and the museum as 'contact zone', but it is also possible to go beyond this to talk about forums of public scholarship, knowledge transaction and local capacity building. (Rassool 2010:15)

Essa ideia permite que vários modelos de museu possam se tornar comunitários, na medida em que em seu cerne está a preocupação com uma metodologia efetivamente dialógica e de compartilhamento, que não compreende a comunidade apenas como público-alvo, mas como sujeito e ator. Museus comunitários não meramente porque são para as comunidades, mas por serem formado por elas. E isso incide diretamente na noção, conforme elucida Rassool, de que os museus comunitários são agentes ativos no processo de produção da própria comunidade, onde deve-se considerar que "Communities are also themselves products of history, and subject to ongoing and contested processes of production and reproduction". (ibdem)

De certo modo, poderíamos perceber os esforços dos dois museus nacionais tanzanianos nesta direção. Contudo, cairíamos no engano de não levarmos em conta que o convite à participação das comunidades (sejam elas representantes de grupos étnicos tanzanianos, stakeholders ou outros agrupamentos específicos interessados, como de artistas) tem sido feito em circunstâncias pontuais, o que não cria métodos contínuos e sólidos de governança. As decisões e condução dos encaminhamentos continuam sendo realizadas pelos seus gestores, vinculados ao 
Estado. Estes e os demais funcionários, muito embora carreguem consigo um olhar de quem também faz parte das "comunidades" 22 sobre e para as quais estes museus falam, estão em uma posição política que inevitavelmente limita e circunscreve suas ações. Os projetos que se abriram para o diálogo e a participação não incentivaram processos de produção de autonomia, mas centraram-se na consulta das partes envolvidas.

Não que esta escuta não seja importante - e isso vale a pena ratificar. Ao contrário, são mecanismos imprescindíveis para museus que se pretendem para as comunidades. Em contextos onde o passado colonial deixou seus legados, estes estão sendo constantemente acionados, (re)apropriados, revistos, modificados. Se nos vários contextos africanos os modos de guardar e perpetuar lembranças, e de definir o que deve ser lembrado, não demandaram (e podem continuar não demandando) os mecanismos e os "lugares de memória" da institucionalização ocidental, faz sentido que novos caminhos sejam fomentados para que essas heranças coloniais (que incluem também as próprias nações e as identidades nacionais) sejam ressignificadas. A "descolonização" nos museus não deve ser pensada apenas em função dos objetos, mas, igualmente, em torno da concepção dos usos destes espaços. 


\section{NOTAS}

1 A partir daqui, adotarei apenas os nomes em inglês, simplesmente como método facilitador para a leitura. Opto por não traduzir para o português para conservar pelo menos esta variação real dos nomes. (Contudo, a forma inglesa é, comumente, menos utilizada na Tanzânia - a não ser em alguns setores mais específicos. Apesar de o inglês ser a língua do colonizador, ele não foi (ainda) incorporado como língua nacional oficial junto ao kiswahili).

2 In Meyer-Heiselberg, R. (ed.) 1972 -Reporting Thirty years'work. Stencil Publications 1. Dar es Salaam: National Museum of Tanzania.

3 Importante fazer referência aqui à "Antropologia da Salvação", que teve o antropólogo alemão Adolf Bastian (1826-1905) como um de seus maiores defensores. Entretanto, é necessário distinguir essa tradição salvacionista alemã das práticas britânicas no Tanganyika, na medida em que a teoria de Bastian buscava descobrir os "padrões elementares de pensamento humano" a partir de objetos coletados em todas as culturas do mundo. Segundo Eriksen e Nielsen (2001), Bastian criticava severamente o evolucionismo unilinear, mas suas construções teóricas antecipavam aquilo que na antropologia alemã iria nortear o pensamento difusionista.

4 Neste momento, o Village Museum ainda não havia sido fundado, estava apenas em fase de idealização e planejamento.

5 Para fazer referência ao que seria a definição de nação para Benedict Anderson (1983).

6 Cf. Kirknæs, J. \& Wembah-Rashid, J. A. R. 1990 [1974] - Introducing Tanzania through the National Museum. Denmark, Bording Grafik.

7 No entanto, além da segregação que continuou existindo - uma vez que aos africanos era proibido o desenvolvimento de atividades capitalistas enquanto que os asiáticos (indianos) continuavam engajados em atividades do setor privado - uma grande crise econômica despontou no país na década de 1980, levando o país à transferência da condição de Estado socialista unipartidário para um modelo multipartidário de liberalismo econômico. Para um aprofundamento sobre as consequências da implementação do Ujamaa, ver Campbell (1975), Chipembere (1976) e Heilman (1998).

8 Até os dias atuais, o discurso moral do Ujamaa e a figura do "father of the nation" continuam sendo acionados pelo partido Chama cha Mapinduzi (no poder desde a independência), como forma de manter a unidade nacional e impedir sua fragmentação. Sobre esses mecanismos que vêm sendo utilizados para refazer e reforçar continuamente um imaginário nacional no pós-socialismo tanzaniano, ver Fouéré (2011).

9 Ali Mazrui chegou a dizer que, neste sentido, "a Europa é, por conseguinte, mãe ilegítima da consciência nacional dos nigerianos, quenianos, marfinenses..." enquanto que o imperialismo ocidental seria "o pai ilegítimo da consciência pan-africana." (2010:8)

10 A ideia dessa expressão é transmitida logo no início da exposição da galeria etnográfica do National Museum and House of Culture, onde os grupos étnicos tanzanianos estão distribuídos em um mapa e seus objetos são apresentados como sendo representações da "riqueza cultural" da Tanzania.

11 Makumbusho é a palavra na língua kiswahili utilizada para denominar Museu.

12 As visitas guiadas no Village Museum, conforme se observa na maioria dos museus, precisam ser contratadas, e estão sujeitas à disponibilidade dos (poucos) guias presentes. Além disso, o conteúdo transmitido aos visitantes varia de acordo com o conhecimento do guia, além das formas de interação que se estabelecem durante uma visita guiada.

13 O programa geralmente contemplava uma etnia ou duas por edição. Porém, nos últimos anos, houve uma alteração neste critério, tendo em vista que levaria décadas para que todos os grupos étnicos tanzanianos pudessem participar se apresentando. Segundo o curador que respondia pelo museu na época do meu trabalho de campo, em 2014, a metodologia agora era "convidar uma determinada região", o que incluía todos os grupos étnicos nela encontrados.

14 CNorbert A. Kayombo e Paul Msemwa foram ambos diretores do National Museums of Tanzania - NMT

15 Curiosamente, quando frequentei o festival em julho de 2016, eu era a única mzungu (categoria em swahili utilizada para designar a pessoa branca ocidental) a acompanhar todos os dias de evento. Cheguei a ver apenas alguns poucos turistas, de passagem. $O$ festival não foi pensado para esse público. 
16 Entrevista concedida a mim pelo curador do Village Museum, Wilbard Lema, em maio de 2014

17 Comunidades e grupos étnicos são categorias constantemente utilizadas de modo intercambiável pelos profissionais desses espaços museológicos.

18 Wilbard conta que quando assumiu a função de curador do Village Museum não havia um banco de dados a respeito dos objetos etnográficos. Algumas legendas sequer existiam mais (ou nunca haviam existido). Ele recorreu, então, a estudantes universitários, de diferentes grupos étnicos tanzanianos, para conseguir completar parte das lacunas encontradas.

19 Como podemos perceber, o National Museum and House of Culture foi submetido a sucessivas mudanças de nome até chegar ao atual, as quais acompanharam as alterações das diretrizes políticas estatais. Sintetizando a ordem dos nomes: King George V Memorial Museum, National Museum of Tanganyika, National Museum of Tanzania, Dar es Salaam National Museum, National Museum and House of Culture. Na década de 1980, passou a se chamar Dar es Salaam National Museum para "ceder" seu nome ao conjunto (administrativo) dos museus nacionais - National Museums of Tanzania.

20 Para ver um pouco mais sobre outras experiências que procuram discutir e colocar em prática as propostas da(s) Nova(s) Museologia(s), e também da Sociomuseologia, indico, dentre outras, a leitura de Dos Santos \& Primo, 2010.

21 Diante de um apelo feito às comunidades locais para a construção de um memorial em homenagem ao recém-falecido rei George V. De acordo com um relatório publicado no The Museums Journal, "Rich people gave much, poor people gave their small contributions and thousands and thousands of people, who could not afford more, gave ten cents each.". Em um outro relato: "It was made possible [a abertura do King George V Memorial Museum] by contributions of money from all communities in the Territory, especially from the Africans some of whome gave what they could even if it was only 5 cents." (Annual Meeting of South African Museums Association, 1941). Cf. Meyer-Heiselberg (1972).

22 Aqui jogando com a ambiguidade da categoria "comunidade", neste contexto estudado, na medida em que ela pode fazer referência tanto aos grupos étnicos tanzanianos quanto aos agrupamentos urbanos definidos em função de localidades, interesses comuns etc. 


\section{REFERÊNCIAS BIBLIOGRÁFICAS}

AMINZADE, R. 2001. "The politics of race and nation: Citizenship and Africanization in Tanganyika". Political Power and Social Theory 14: 53-90.

ANDERSON, B. 1983. Imagined Communities: reflections on the origin and spread of nationalism. Londres: Verso.

BARTH, F. 1969. "Introduction”. In Ethnic Groups and Boundaries. Londres: G. Allen and Unwin.

CAMPBELL, H. 1975. "Socialism in Tanzania: A case study". The black scholar 6(8): 41-51.

CHATTERJEE, P. 1986. Nationalist Thought and the Colonial World. London: Zed Books.

1993. The Nation and its Fragments: Colonial and Postcolonial Histories. Princeton: Princeton University Press.

CHIPEMBERE, H. B. M. 1976. "Kenyan and Tanzanian Socialism (A Comparative Study)". Ufahamu: a journal of African studies 7(1)

COMAROFF, J. \& COMAROFF, J. 1992. Ethnography and the Historical Imagination. San Francisco \& Oxford: Westview Press.

DE L'ESTOILE, B. 2008. “The past as it lives now: an anthropology of colonial legacies”. Social Anthropology 16 (3): $267-279$. 2010. Le Goût des Autres. De l'Exposition colonial aux Arts premiers. Paris : Flammarion.

2011. "A vida selvagem em vitrine: reflexões sobre os animais em museus". Proa: Revista de Antropologia e Arte 1(3).

DOS SANTOS, P. A.; PRIMO, J. (eds). 2010. Sociomuseology 3 - Cadernos de Sociomuseologia 37: To understand New Museology in the 21st Century. Edições Universitárias Lusófonas.

ERIKSEN, T.B. \& FINN, S. N. 2001. A history of anthropology. London: Pluto Press.

FOUÉRÉ, M-A. 2011. “Tanzanie : la nation à l'épreuve du postsocialisme”. Politique africaine 121: 69-85.

HARRISON, S. 2003. "Cultural difference as denied resemblance: reconsidering Nationalism and Ethnicity". Comparative Studies in Society and History 45 (2).

HEILMAN, B. 1998. “Who are the Indigenous Tanzanians?” Africa Today 45 (3/4): 369-387.

KAYOMBO, N. A. 2005. General guidelines for establishment and management of museums in Tanzania. Dar es Salaam: Dar es Salaam University Press.

KIRKAES, J.; WEMBAH-RASHID, J. A. R. 1990. Introducing Tanzania through the National Museum. Denmark: Bording Grafik.

MALIK, K. 1996. The Meaning of Race. Londres: Mac Millan.

MAZRUI, A. (ed.) 2010. A história geral da África VIII. Brasília, Unesco.

MEYER-HEISELBERG, R. (ed.) 1972. Reporting Thirty years'work. Stencil Publications 1. Dar es Salaam: National Museum of Tanzania.

MPANGALA, G. 1998. "Benefits and dangers of presenting different ethnic cultures at Museums". In MSEMWA, P. J. Proceedings of a Conference on African Open Air Museums. Dar es Salaam: National Museum of Tanzania, pp.13-18. 
MSEMWA, P. 2010. "The National Museum Dar es Salaam transformation into National Museum and House of Culture". In City Museum on the move - A dialogue between professionals from African countries, the Netherlands and Belgium. Amsterdam.

RASSOOL, C. 2010. "Introduction: the community museum" In Tamara van Kessel, Renée Kistemaker \& Léontine Meijervan Mensch (eds.) City Museum on the move - A dialogue between professionals from African countries, the Netherlands and Belgium. Amsterdam: Amsterdam Museum / Reindwardt Academy / University of Amsterdam. Disponível em: https:// hart.amsterdam/image/2015/8/12/city_museum_on_the_move.pdf

RENAN, E. 1990 [1882]. "What is a Nation?" In Bhabha, H.K. (ed.) Nation and Narration. Londres: Routledge.

STOCKING Jr., G. (ed.). 1988. Objects and Others: Essays on Museums and Material Culture. Wisconsin: The University of Wisconsin Press.

THOMAS, N. 1991. Entangled objects: exchange, material culture and colonialism in the Pacific. Cambridge / London: Harvard University Press.

TSING, A. L. 1993. In the Realm of the Diamond Queen: Marginality in an Out-of-the-Way Place. Princeton: Princeton University Press. 


\section{Legados coloniais e a produção de ambivalências: dos encontros, desencontros e conciliações em dois museus nacionais da Tanzânia, África.}

\section{RESUMO}

Os dois museus nacionais mais antigos da Tanzânia nasceram de projetos do empreendimento colonial britânico. Para além de terem sido apropriados pelos objetivos de construção do estado nacional, estes museus e suas coleções etnográficas continuaram atraindo substancialmente o interesse de turistas ocidentais. As comunidades locais (ou nacionais), entretanto, pareciam não se identificar com estes espaços que procuravam reificar a consolidação de identidades e de uma unidade nacional. O trabalho etnográfico nesses museus e a investigação de suas trajetórias e contextos históricos permitiram uma análise de processos políticos relacionados à construção de identidades e identificações. O artigo em questão procura evidenciar as ambivalências de propósitos que advêm dos encontros provocados nesses museus, algo que aponta não apenas para uma coexistência de (re)significações, mas, sobretudo, para compreensões que aparecem como possíveis para repensar os sentidos do espaço museológico em contextos africanos.

PALAVRAS-CHAVE: museus nacionais; identidades; Tanzania; legados coloniais; África

\section{Colonial legacies and the production of ambivalences: from meetings, disagreements and conciliations in two national museums in Tanzania, Africa}

\section{ABSTRACT}

The two earliest museums of Tanzania were born as projects of the British colonial enterprise. Besides having served the Tanzanian nation-building process' aims, these museums and their ethnographic collections kept attracting Western tourists. The local (or national) communities, however, seemed not identify themselves with these places, where national identities and unity had been reified. Through ethnographic work and historical investigation, it was possible to analyze political processes concerning the production of both identities and identification. This article seeks to shed light on ambivalences that arise from encounters in these museums, something which does not only uncover the coexistence of different meanings, but elucidates other ways of thinking about museums in African contexts.

KEYWORDS: ational museums; identities; Tanzania; colonial legacies; Africa

Recebido em: 17/02/2016

Aprovado em: 23/11/2016 